\title{
IC-Topological Spaces and Applications in Soft Computing
}

\author{
Subrata Bhowmik \\ Department of Mathematics, Tripura University \\ Suryamaninagar, Tripura, India-799130 \\ subrata_bhowmik_math@rediffmail.com
}

\begin{abstract}
The objective of this paper is to generalize the concept of topological space so that concepts of approximation spaces like Rough set, Pre-topological space, Approximation spaces generated by arbitrary relation etc. including topological space can be study by a single space. Here we considered a non-empty set $\mathrm{X}$ with two unary operators i and $\mathrm{c}$ on the power set $\wp(\mathrm{X})$ called respectively the interior and closure operators with some conditions on the operators. We will call the order triplet (X, i, c) an Interior-Closure Topological space or Simply IC-Topological space. In this paper we will discuss some applications of such spaces in real life problems.
\end{abstract}

Keywords: Topological Spaces, Incomplete information system.

\section{IC-Topological Spaces}

In the theory of different types of "Approximation spaces" like Rough set approximation space, Pre-topological space, Approximation by covering, Approximation spaces generated by a relation etc., the interior/lower approximation and closure/upper approximation of subsets may not be the interior and closure of the subsets with respect to a topology on the set. In this paper we will generalize the concept of topological space so that all these concepts can unified in a single space or its weaker space. This type of newly defined space can be useful in the study of "Approximation spaces" and also a useful tool in the the solution of real life problems like - diagnosis, data compression etc. by establishing soft computing techniques.

Definition 1. Let $\mathrm{X}$ be a non-empty set, we consider two unary operators $\mathrm{i}$ and c on $\wp(\mathrm{X})$, i.e. we consider two operators i $: \wp(\mathrm{X}) \rightarrow \wp(\mathrm{X})$ and $\mathrm{c}: \wp(\mathrm{X}) \rightarrow \wp(\mathrm{X})$ satisfying the following conditions:

1. For any $\mathrm{A} \subseteq \mathrm{X}, \mathrm{i}(\mathrm{A}) \subseteq \mathrm{c}(\mathrm{A})$ or simply $\mathrm{i} \subseteq \mathrm{c}$.

2. $\mathrm{i}^{2}=\mathrm{ii}=\mathrm{i}$ and $\mathrm{c}^{2}=\mathrm{cc}=\mathrm{c}$

3. $\mathrm{i}$ and $\mathrm{c}$ are monotone increasing, i.e. if $\mathrm{A} \subseteq \mathrm{B} \subseteq \mathrm{X}$ then $\mathrm{i}(\mathrm{A}) \subseteq \mathrm{i}(\mathrm{B})$ and $\mathrm{c}(\mathrm{A}) \subseteq \mathrm{c}(\mathrm{B})$

4. $\mathrm{c}(\varnothing)=\varnothing, \mathrm{i}(\mathrm{X})=\mathrm{X}$ 
The unary operators $\mathrm{i}$ and $\mathrm{c}$ are respectively called a interior operator and a closure operator on $\mathrm{X}$ and the order triplet $(\mathrm{X}, \mathrm{i}, \mathrm{c})$ is called a interior-closure topological space or simply IC-topological space.

For any $\mathrm{A} \subseteq \mathrm{X}$ we will say $\mathrm{i}(\mathrm{A})$ is the lower approximation of $\mathrm{A}$ and $\mathrm{c}(\mathrm{A})$ is the upper approximation of $\mathrm{A}$ in the IC-topological space (X, i, c).

If we omit the condition (1), then the order triplet (X, i, c) is called quasi-ICtopological space or qIC-topological space; if we omit the condition (2) only, then the order triplet $(\mathrm{X}, \mathrm{i}, \mathrm{c})$ is called pseudo IC-topological space or pIC-topological space and if we omit both the conditions (1) and (2), then the order triplet (X, $\mathrm{i}, \mathrm{c})$ is called quasi-pseudo-IC-topological space or qpIC-topological space,

For a IC-topological space (or qIC or pIC-topological space) (X, i, c) a subset $\mathrm{U} \subseteq \mathrm{X}$ is called an open set if $\mathrm{i}(\mathrm{U})=\mathrm{U}$ and a subset $\mathrm{F} \subseteq \mathrm{X}$ is called a closed set if $\mathrm{c}(\mathrm{F})=\mathrm{F}$. It is easy to see that the whole set $\mathrm{X}$ is an open set and the empty set $\varnothing$ is a closed set.

Example 2. (i) Any topological approximation space $(\wp(\mathrm{X}), \mathcal{O}(\mathrm{X}), \mathcal{C}(\mathrm{X}), l, u)$ induced from a topological space $(\mathrm{X}, \mathcal{B})$ (see Cattaneo[1]), $(\mathrm{X}, l, u)$ is an ICTopological space. We can also in similar way generate IC-topological space taking a supra topological space in the above approximation space.

(ii) If int and $\mathrm{cl}$ are interior and closure operator on a non-empty set $\mathrm{X}$ (see Zhu [10]) then (X, int, $c l$ ) ia an IC-topological space.

(iii) Let $\mathrm{R}$ be relation on a non-empty set $\mathrm{X}$, for each $\mathrm{x} \in \mathrm{X}$ we define $\mathrm{R}_{x}=\{\mathrm{y} \in \mathrm{X}: \mathrm{xRy}\}$. We define unary operations $\mathrm{i}$ and $\mathrm{c}$ on the power set $\wp(\mathrm{X})$ as: for any subset $A$ of $X$ we define $i(A)=\left\{x \in X: R_{x} \subseteq A\right\}$ and $c(A)=\left\{x \in X: R_{x} \cap A \neq \varnothing\right\}$. It is very easy to see that $(\mathrm{X}, \mathrm{i}, \mathrm{c})$ is a qpIC topological space.

(iv) For any rough set approximation space (X, R) generated by an equivalence relation $\mathrm{R}$ on $\mathrm{X}$ (see Pawlak[6]), if - and - be the lower and upper approximation operators respectively, then $\left(\mathrm{X},-,{ }^{-}\right)$is an IC-topological space.

(v) If $(\wp(\mathrm{X}), \cap, \cup, \sim, \mathbf{L}, \mathbf{H})$ is a rough set algebra (see Yao[9]), then (X, $\mathbf{L}$, $\mathbf{H})$ is a qpIC-topological space.

(vi) For a pre-topological space $(\mathrm{X}, \varepsilon, \kappa)$ (see Pagliani and Chakraborty[5]), if $\mathrm{I}$ and $\mathrm{C}$ are corresponding $\kappa$-interior and $\varepsilon$-closure operator respectively then $(\mathrm{X}, \mathrm{I}, \mathrm{C})$ is a IC-topological space.

Some properties of the IC-topological spaces are listed below, the proofs are easy forward, so proofs are omitted

Theorem 3. For a IC-topological space $(X, i, c)$, for any $A, B \subseteq X$, $i(A \cap B) \subseteq i(A) \cap i(B)$ and $c(A) \cup c(B) \subseteq c(A \cup B)$

Theorem 4. For a $I C$-topological space $(X, i, c)$, for $A \in X, i(A)$ contains every open set contained in $A$ and $c(A)$ is contained in every closed set containing $A$ or in other word $\cup\{U: U \in \mathcal{O} O(X)$ and $U \subseteq A\} \subseteq i(A)$ and $c(A) \subseteq \cap\{F: F \in \mathcal{C}(X)$ and $A \subseteq F\}$. 
Theorem 5. For a $I C$-topological space $(X, i, c)$ for any $A \subseteq X$ the conditions $i(X-A)=X-c(A)$ and $c(X-A)=X-i(A)$ are equivalent.

Definition 6. A IC-topological space $(\mathrm{X}, \mathrm{i}, \mathrm{c})$ is said to be

(i) proper if for any $\mathrm{A} \subseteq \mathrm{X}, \mathrm{i}(\mathrm{A}) \subseteq \mathrm{A} \subseteq \mathrm{c}(\mathrm{A})$,

(ii) with duality if for any $\mathrm{A} \subseteq \mathrm{X}, \mathrm{i}(\mathrm{X}-\mathrm{A})=\mathrm{X}-\mathrm{c}(\mathrm{A})$.

Example \%. The IC-topological space generated by a rough set approximation is a proper IC-topological space with duality.

Theorem 8. For a IC-topological space $(X, i, c)$ with duality,

(i) for any $A \subseteq X$ the conditions (i) $i(A) \subseteq A$ and (ii) $A \subseteq c(A)$ are equivalent.

(ii) $U \subseteq X$ is open iff $X-U$ is closed.

\section{Application in Soft Computing When the Information from the Data Is Incomplete}

IC-topological spaces can be use to apply in such problem like prediction, data compression etc which will be discussed in this section. Here the problems are associated with the decision with incomplete information. Before going to apply IC-topological spaces in these type of problems, let us first know the definition of incomplete information system. Following Shao[7], Cattanio[1], Kryszkiewicz[2] we define an incomplete information as:

Definition 9. An Incomplete information system (IIS) is a structure $\mathfrak{K}=(\mathrm{X}, A t t$, Val, F) where

(i) $\mathrm{X}$ is a non-empty set called the sample space,

(ii) Att is a non-empty set called the set of attributes,

(iii) $V a l=\{\mathrm{Y}, \mathrm{N}\}$ called the set of values of attributes associated with the members of $\mathrm{X}(\mathrm{Y}=\mathrm{Yes}, \mathrm{N}=\mathrm{No})$, and

(iv) $F=\left\{\mathrm{f}_{a}: \mathrm{a} \in A t t\right\}$ is a set of mappings called the attributive decision functions defined as: for each a $\in A t t$ there exists a non-empty subset $\mathrm{X}_{a} \subseteq \mathrm{X}$ such that $\mathrm{f}_{a}: \mathrm{X}_{a} \rightarrow$ Val.

If $\mathrm{X}_{a}=\mathrm{X}$ for each $\mathrm{a} \in A t t$ the information system $\mathfrak{K}=(\mathrm{X}, A t t, V a l, F)$ is said to be complete(CIS).

Now let us assume that for each $a \in A$ tt there exists $\mathrm{x} \in \mathrm{X}_{a}$ such that $\mathrm{f}_{a}(\mathrm{x})=\mathrm{Y}$ and for each $\mathrm{x} \in \mathrm{X}, \exists \mathrm{a} \in A t t$ such that $\mathrm{x} \in \mathrm{X}_{a}$ with $\mathrm{f}_{a}(\mathrm{x})=\mathrm{Y}$. us define two operators $\mathrm{s}: A t t \rightarrow \wp(\mathrm{X})$ and $\mathrm{m}: A t t \rightarrow \wp(\mathrm{X})$ as

$$
\mathrm{s}(\mathrm{a})=\left\{\mathrm{x} \in: \mathrm{f}_{a}(\mathrm{x})=\mathrm{Y}\right\}, \mathrm{m}(\mathrm{a})=\left\{\mathrm{x} \in \mathrm{f}_{a}(\mathrm{x})=\mathrm{Y}\right\} \cup\left(\mathrm{X}-\mathrm{X}_{a}\right)
$$

We will say $\mathrm{s}(\mathrm{a})$ is the set having attribute "a" surely and $\mathrm{m}(\mathrm{a})$ is the set having attribute "a" possibly, but no one outside $\mathrm{m}(\mathrm{a})$ has the value of the attribute "a" "N".

Let us define attributes "1" and " $0 "$ and consider the information system $\mathfrak{K}=\left(\mathrm{X}, A t t^{\prime}, \mathrm{Val}^{\prime}, F^{\prime}\right)$ where $A t t^{\prime}=A t t \cup\{0,1\}$ and $\operatorname{Val}^{\prime}=\operatorname{Val} \cup\left\{\mathrm{f}_{0}, \mathrm{f}_{1}\right\}$ and $\mathrm{X}_{1}=\mathrm{X}=\mathrm{X}_{0}$, the attribute of possibly any one of the attribute that $\mathrm{f}_{1}(\mathrm{x})=\mathrm{Y}$ 
and $\mathrm{f}_{0}(\mathrm{x})=\mathrm{N}$ for each $\mathrm{a} \in \mathrm{X}$. So $\mathrm{s}(1)=\mathrm{X}=\mathrm{m}(1)$ and $\mathrm{s}(0)=\varnothing=\mathrm{m}(0)$. We can say attribute " 1 " is characterized as: for each $\mathrm{x} \in \mathrm{X}$ " 1 " is the attribute having at least any one of the attribute from $A t t$ with "Y" and "0" is characterized as: for each $\mathrm{x} \in \mathrm{X}$ " 0 " is the attribute having all the attribute from Att with "N".

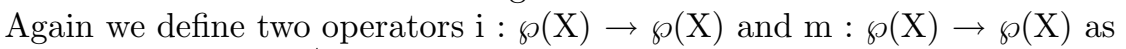

$\mathrm{i}(\mathrm{A})=\cup\left\{\mathrm{s}(\mathrm{a}): \mathrm{a} \in A t t^{\prime}\right.$ and $\left.\mathrm{s}(\mathrm{a}) \subseteq \mathrm{A}\right\}$

$\mathrm{c}(\mathrm{A})=\cap\left\{\mathrm{m}(\mathrm{a}): \mathrm{a} \in A t t^{\prime}\right.$ and $\left.\mathrm{A} \subseteq \mathrm{m}(\mathrm{a})\right\}$

It is easy to see that $\mathrm{i}(\mathrm{A}) \subseteq \mathrm{A} \subseteq \mathrm{c}(\mathrm{A})$.

Theorem 10. $(X, i, c)$ is a IC-topological space.

Proof. 1. $\mathrm{i} \subseteq \mathrm{c}$ follows from the definition of $\mathrm{i}$ and $\mathrm{c}$.

2. For $\mathrm{A} \subseteq \mathrm{X}$, $\mathrm{i}(\mathrm{A}) \subseteq \mathrm{A}$, so $\mathrm{i}(\mathrm{A}) \subseteq \mathrm{i}(\mathrm{A})$. Let $\mathrm{x} \in \mathrm{i}(\mathrm{A})$, so $\mathrm{x} \in \mathrm{s}(\mathrm{a}) \subseteq \mathrm{A}$, so $\mathrm{x} \in \mathrm{s}(\mathrm{a}) \subseteq \mathrm{i}(\mathrm{A})$, i.e. $\mathrm{x} \in \mathrm{ii}(\mathrm{A})$, so $\mathrm{ii}=\mathrm{i}$.

For $\mathrm{A} \subseteq \mathrm{X}, \mathrm{A} \subseteq \mathrm{c}(\mathrm{A})$, so $\mathrm{c}(\mathrm{A}) \subseteq \mathrm{cc}(\mathrm{A})$. Let $\mathrm{x} \in \mathrm{cc}(\mathrm{A})$, so $\mathrm{x} \in \mathrm{m}(\mathrm{a})$ for any $\mathrm{a} \in A t t^{\prime}$ with $\mathrm{c}(\mathrm{A}) \subseteq \mathrm{m}(\mathrm{a})$, now for any $\mathrm{a} \in A t t^{\prime}$ with $\mathrm{A} \subseteq \mathrm{m}(\mathrm{a}) \Rightarrow \mathrm{c}(\mathrm{A}) \subseteq \mathrm{m}(\mathrm{a})$, but $\mathrm{x} \in \mathrm{m}(\mathrm{a})$, i.e. $\mathrm{x} \in \mathrm{c}(\mathrm{A})$, so $\mathrm{cc}=\mathrm{c}$.

3. $\mathrm{i}$ and $\mathrm{c}$ both are monotonic according to the definition of $\mathrm{i}$ and $\mathrm{c}$.

4. $\mathrm{s}(1) \subseteq \mathrm{X}$ so $\mathrm{i}(\mathrm{X})=\mathrm{X}, \varnothing \subseteq \mathrm{m}(0)$ so $\mathrm{c}(\varnothing)=\varnothing$.

Hence (X, i, c) is a IC-topological space.

We define two operators I $: \wp(\mathrm{X}) \rightarrow \wp(\mathrm{X})$ and $\mathrm{C}: \wp(\mathrm{X}) \rightarrow \wp(\mathrm{X})$ as

$$
\begin{aligned}
& \mathrm{I}(\mathrm{A})=\cup\{\mathrm{s}(\mathrm{a}): \mathrm{a} \in A t t \text { and } \mathrm{s}(\mathrm{a}) \cap \mathrm{A} \neq \varnothing\} \\
& \mathrm{C}(\mathrm{A})=\cup\{\mathrm{m}(\mathrm{a}): \mathrm{a} \in A t t \text { and } \mathrm{m}(\mathrm{a}) \cap \mathrm{A} \neq \varnothing\}
\end{aligned}
$$

It is very easy to see that:

Theorem 11. $(X, I, C)$ is a pIC-topological space.

We again define two operators $\iota: \wp(\mathrm{X}) \rightarrow \wp(\mathrm{X})$ and $\varepsilon: \wp(\mathrm{X}) \rightarrow \wp(\mathrm{X})$ as

$$
\begin{aligned}
& \iota(\mathrm{A})=\cup\{\mathrm{s}(\mathrm{a}): \mathrm{a} \in A t t \text { and } \mathrm{s}(\mathrm{a}) \subseteq \mathrm{A}\} \\
& \varepsilon(\mathrm{A})=\cup\{\mathrm{m}(\mathrm{a}): \mathrm{a} \in A t t \text { and } \mathrm{m}(\mathrm{a}) \cap \mathrm{A} \neq \varnothing\}
\end{aligned}
$$

It is also very easy to see that:

Theorem 12. $(X, \iota, \varepsilon)$ is a pIC-topological space.

For any IIS we can generate different types of approximation spaces as ICtopological spaces as in Theorem10-12.

\subsection{A Model of Decision Making When the Information from the Data Is Incomplete}

Let $\mathrm{S}$ be a set or universes of elements with large numbers of objects and $\left\{\mathrm{a}_{1}, \mathrm{a}_{2}\right.$, $\left.\ldots, \mathrm{a}_{n} ; \mathrm{b}_{1}, \mathrm{~b}_{2}, \ldots, \mathrm{b}_{m}\right\}$, be $\mathrm{n}+\mathrm{m}$ attributes. Let us say $\mathrm{a}_{k}$ 's are symptom attributes and $\mathrm{b}_{j}$ 's are decision attributes. The information is that all the members of $\mathrm{S}$ having at least one attribute with value " $\mathrm{Y}$ " and also the information is incomplete. Now the problem is: we are to decide if we pick up an object of S say " $\mathrm{x}$ " and observing the symptom attributes of " $\mathrm{x}$ " we are to decide which decision 
attribute is the concluding decision for " $\mathrm{x}$ ". Another problem is if we select a subset $\mathrm{W}$ of $\mathrm{S}$, then which decision attribute is corresponding to $\mathrm{W}$.

For this let us take a subset $\mathrm{X}$ of $\mathrm{S}$ of suitable size and consider the IISs (X, $\operatorname{Att}(\mathrm{A}), \operatorname{Val}, F(\mathrm{~A}))$ and $(\mathrm{X}, \operatorname{Att}(\mathrm{B}), \operatorname{Val}, F(\mathrm{~B}))$, where

$$
\begin{aligned}
& A t t(\mathrm{~A})=\left\{\mathrm{a}_{1}, \mathrm{a}_{2}, \ldots \ldots ., \mathrm{a}_{n}\right\} \\
& \operatorname{Att}(\mathrm{B})=\left\{\mathrm{b}_{1}, \mathrm{~b}_{2}, \ldots \ldots ., \mathrm{b}_{n}\right\}
\end{aligned}
$$

We now construct the IC-topological spaces $\left(\mathrm{X}, \mathrm{i}_{A}, \mathrm{c}_{A}\right)$ and $\left(\mathrm{X}, \mathrm{i}_{B}, \mathrm{c}_{B)}\right)$ according to Theorem10, qIC-topological spaces $\left(\mathrm{X}, \mathrm{I}_{A}, \mathrm{C}_{A}\right)$ ) and $\left(\mathrm{X}, \mathrm{I}_{B}, \mathrm{C}_{B}\right)$ ) according to Theorem11, $\left(\mathrm{X}, \iota_{A}, \varepsilon_{A}\right)$ and $\left(\mathrm{X}, \iota_{B}, \varepsilon_{B}\right)$ according to Theorem12.

\subsubsection{Decision Model}

For example let $\left\{\mathrm{a}_{1}, \mathrm{a}_{2}, \ldots, \mathrm{a}_{k}\right\}$ be a set of attributes corresponding to " $\mathrm{x}$ ", now we are to decide whether " $\mathrm{x}$ " has the decision attribute $\mathrm{b}_{j}$ or not. For this we can apply the following method:

Let (I) $\mathrm{s}\left(\mathrm{a}_{1}\right) \cap \mathrm{s}\left(\mathrm{a}_{2}\right) \cap \quad \ldots . \cap \mathrm{s}\left(\mathrm{a}_{k}\right) \subseteq \mathrm{s}\left(\mathrm{b}_{j}\right)$ and (II) $\mathrm{m}\left(\mathrm{a}_{1}\right) \cup \mathrm{m}\left(\mathrm{a}_{2}\right) \cup \quad \ldots$ $\cup \mathrm{m}\left(\mathrm{a}_{k}\right) \supseteq \mathrm{m}\left(\mathrm{b}_{j}\right)$, i.e. if some one having the attributes $\mathrm{a}_{1}, \mathrm{a}_{2}, \ldots, \mathrm{a}_{k}$ surely is surely with the attribute $b_{j}$ and if some one have the possibility of the decision $\mathrm{b}_{j}$ then it have the possible attributes $\mathrm{a}_{1}, \mathrm{a}_{2}, \ldots, \mathrm{a}_{k}$, some or all but no need of more attributes for possibility of $b_{j}$.

Here we will conclude that " $\mathrm{x}$ " has the decision attribute $\mathrm{B}_{j}$. If the collection $\left\{\mathrm{a}_{1}, \mathrm{a}_{2}, \ldots ., \mathrm{a}_{k}\right\}$ is a smallest collection to hold the above conditions, we say that with the least symptom attributes $\left\{a_{1}, a_{2}, \ldots, a_{k}\right\}$ an element has the decision attribute $\mathrm{b}_{j}$. We will say $\left\{\mathrm{a}_{1}, \mathrm{a}_{2}, \ldots, \mathrm{a}_{k}\right\}$ is a LSDAC (Least Symptom Decisional Attribute Class) for $\mathrm{b}_{j}$.

\subsubsection{Decision Model}

Let $\mathrm{W}$ be any subset of $\mathrm{S}$ and we are to decide which decision attribute should be associate with $\mathrm{W}$. For that we consider the following method:

Let $\mathrm{U}=\mathrm{W} \cap \mathrm{X}$, if $1 . \mathrm{i}_{A}(\mathrm{U}) \supseteq \mathrm{s}\left(\mathrm{b}_{j}\right)$ and $2 . \mathrm{c}_{A}(\mathrm{U}) \subseteq \mathrm{m}\left(\mathrm{b}_{j}\right)$, i.e. 1. any one having the decision attribute $\mathrm{b}_{j}$ surely then it has at least one or more attributes surely, whose surety is (are) only seen in the class $U$ is and 2. if any one have the possibility of the common symptom attributes that are possibly common to all the members in the class $\mathrm{U}$, have the possibility of the decision attribute $\mathrm{b}_{j}$. Here we will decide that $\mathrm{b}_{j}$ is a decision attribute corresponding to $\mathrm{Y}$.

If we replace the space $\left(\mathrm{X}, \mathrm{i}_{A}, \mathrm{c}_{A}\right)$ by $\left(\mathrm{X}, \iota_{A}, \varepsilon_{A}\right)$ then the conclusion obtained can be treated as stronger conclusion than the above and if replace by $\left(\mathrm{X}, \mathrm{I}_{A}\right.$, $\mathrm{C}_{A}$ ) then the conclusion can be treated as weaker conclusion than the above.

We can revert the role of symptom attribute and decision attributes in above, we can find the cause of a single symptom attribute in multiple decision attributes.

Example 13. Here we are going to see how the above model can be applied in Hospital Management. Here the example is only for example not on actual data or medical fact, this example is only to understand the application of above method. 
Let in a hospital from some patients we have the following information(recorder data):

\begin{tabular}{|c|c|c|c|c|c|c|}
\hline Patient & Fever $\left(\mathrm{a}_{1}\right)$ & Headac. $\left(\mathrm{a}_{2}\right)$ & Indg. $\left(\mathrm{a}_{3}\right)$ & Cough $\left(\mathrm{a}_{4}\right)$ & Flue $\left(\mathrm{b}_{1}\right)$ & Stom.Inf. $\left(\mathrm{b}_{2}\right)$ \\
\hline $\mathrm{x}_{1}$ & $\mathrm{Y}$ & $\mathrm{Y}$ & $\mathrm{Y}$ & $\mathrm{Y}$ & $\mathrm{Y}$ & $\mathrm{Y}$ \\
\hline $\mathrm{x}_{2}$ & $\mathrm{Y}$ & $\mathrm{Y}$ & $\mathrm{N}$ & $\mathrm{Y}$ & $\mathrm{Y}$ & $?$ \\
\hline $\mathrm{x}_{3}$ & $?$ & $\mathrm{~N}$ & $\mathrm{~N}$ & $?$ & $\mathrm{Y}$ & $\mathrm{N}$ \\
\hline $\mathrm{x}_{4}$ & $\mathrm{~N}$ & $\mathrm{~N}$ & $\mathrm{~N}$ & $\mathrm{Y}$ & $?$ & $\mathrm{~N}$ \\
\hline $\mathrm{x}_{5}$ & $\mathrm{~N}$ & $\mathrm{Y}$ & $?$ & $?$ & $\mathrm{~N}$ & $?$ \\
\hline
\end{tabular}

Here the symptom attributes are $\left\{a_{1}, a_{2}, a_{3}, a_{4}\right\}$ and decision attributes are $b_{1}$ and $b_{2}$. Now,

$$
\begin{aligned}
& \mathrm{X}=\left\{\mathrm{x}_{1}, \mathrm{x}_{2}, \mathrm{x}_{3}, \mathrm{x}_{4}, \mathrm{x}_{5}\right\} \\
& \mathrm{s}\left(\mathrm{a}_{1}\right)=\left\{\mathrm{x}_{1}, \mathrm{x}_{2}\right\}, \mathrm{m}\left(\mathrm{a}_{1}\right)=\left\{\mathrm{x}_{1}, \mathrm{x}_{2}, \mathrm{x}_{3}\right\} \\
& \mathrm{s}\left(\mathrm{a}_{2}\right)=\left\{\mathrm{x}_{1}, \mathrm{x}_{2}, \mathrm{x}_{5}\right\}, \mathrm{m}\left(\mathrm{a}_{2}\right)=\left\{\mathrm{x}_{1}, \mathrm{x}_{2}, \mathrm{x}_{5}\right\} \\
& \mathrm{s}\left(\mathrm{a}_{3}\right)=\left\{\mathrm{x}_{1}\right\}, \mathrm{m}\left(\mathrm{a}_{3}\right)=\left\{\mathrm{x}_{1}, \mathrm{x}_{5}\right\} \\
& \mathrm{s}\left(\mathrm{a}_{4}\right)=\left\{\mathrm{x}_{1}, \mathrm{x}_{2}, \mathrm{x}_{4}\right\}, \mathrm{m}\left(\mathrm{a}_{4}\right)=\mathrm{X} \\
& \mathrm{s}\left(\mathrm{b}_{1}\right)=\left\{\mathrm{x}_{1}, \mathrm{x}_{2}, \mathrm{x}_{3}\right\}, \mathrm{m}\left(\mathrm{b}_{1}\right)=\left\{\mathrm{x}_{1}, \mathrm{x}_{2}, \mathrm{x}_{3}, \mathrm{x}_{4}\right\}, \\
& \mathrm{s}\left(\mathrm{b}_{2}\right)=\left\{\mathrm{x}_{1}\right\}, \mathrm{s}\left(\mathrm{b}_{2}\right)=\left\{\mathrm{x}_{1}, \mathrm{x}_{2}, \mathrm{x}_{5}\right\} .
\end{aligned}
$$

Obviously $\mathrm{s}(0)=\varnothing$ and $\mathrm{m}(1)=\mathrm{X}$.

Now the collection $\left\{a_{1}, a_{4}\right\}$ is the LSDAC for the decision, since (I) $s\left(a_{1}\right) \cap s\left(a_{4}\right)$ $\subseteq \mathrm{s}\left(\mathrm{b}_{1}\right)$ and $(\mathrm{II}) \mathrm{m}\left(\mathrm{a}_{1}\right) \cup \mathrm{m}\left(\mathrm{a}_{4}\right) \supseteq \mathrm{m}\left(\mathrm{b}_{1}\right)$.

Now we can decide that if a person coming to the hospital with symptoms "Fever" and "Cough" then we will make a decision that the patient is with "Flue". In this case the patient can say that he has the problem of "Headache" or "Indigestion" or not. For example if a patient comes with the symptoms $\left\{\mathrm{a}_{1}\right.$, $\left.\mathrm{a}_{2}, \mathrm{a}_{4}\right\}$ then it is easy to see that the corresponding decision is also "Flue". Here $\left\{\mathrm{a}_{1}, \mathrm{a}_{4}\right\}$ is a LSDAC for "Flue $\left(\mathrm{b}_{1}\right)$ ".

Similarly $\left\{\mathrm{a}_{1}, \mathrm{a}_{3}\right\}$ is a LSDAC for "Stomach Infection $\left(\mathrm{b}_{2}\right)$ ".

Again Let $\mathrm{U}=\left\{\mathrm{x}_{1}, \mathrm{x}_{2}\right\}$ is the portion of a community say " $\mathrm{T}$ " of the region ( $\mathrm{T}$ is a specific subset of the population of the region of the hospital). Now, $\mathrm{i}(\mathrm{U})=\mathrm{s}\left(\mathrm{a}_{1}\right) \cup \mathrm{s}\left(\mathrm{a}_{3}\right)=\left\{\mathrm{x}_{1}, \mathrm{x}_{2}\right\}$ and $\mathrm{c}(\mathrm{U})=\mathrm{m}\left(\mathrm{a}_{1}\right) \cap \mathrm{m}\left(\mathrm{a}_{2}\right) \cap \mathrm{m}\left(\mathrm{a}_{4}\right)=\left\{\mathrm{x}_{1}, \mathrm{x}_{2}\right\}$. We see that $\mathrm{i}(\mathrm{U}) \supseteq \mathrm{s}\left(\mathrm{b}_{2}\right)$ and $\mathrm{c}(\mathrm{U}) \subseteq \mathrm{m}\left(\mathrm{b}_{2}\right)$.

Now we can make a decision that the disease $b_{2}$ is generally confined in the community "T" and if a patient come from the community "T" and if he suffering from the $\mathrm{b}_{2}$ then we can suspect whether this infection comes from his community or not and if he is not ill or we can expect the possibility of the infection $b_{2}$ due to his community(in case of communicative disease).

\subsection{Decision of Change of Set of Attributes}

Let $S$ be a population and $A=\left\{a_{1}, a_{2}, \ldots ., a_{n}\right\}$ and $B=\left\{b_{1}, b_{2}, \ldots \ldots, b_{m}\right\}$ be two set of attributers in two different stages, $\mathrm{A}$ is initial stage and $\mathrm{B}$ is the final stage. The information is all the members of $\mathrm{S}$ having at least one attribute from the two sets of attributes. Now the problem is: we are to decide whether the initial attributes changed to the final attributes or not. Let $\mathrm{X}$ be a sample of suitable 
size from the population, but the sample having with incomplete information regarding the attributes we construct the $\mathrm{IC}$-topological space $\left(\mathrm{X}, \mathrm{i}_{A}, \mathrm{c}_{B}\right)$ with the set of attributes $\mathrm{A}$ and $\left(\mathrm{X}, \mathrm{i}_{B}, \mathrm{c}_{B}\right)$ with the set of attributes $\mathrm{B}$.

\subsubsection{Decision Model}

If (1) $\mathrm{U}$ is open in $\left(\mathrm{X}, \mathrm{i}_{B}, \mathrm{c}_{B}\right)$ then $\mathrm{U}$ is open in $\left(\mathrm{X}, \mathrm{i}_{A}, \mathrm{c}_{A}\right)$ and (2) F is closed in $\left(\mathrm{X}, \mathrm{i}_{B}, \mathrm{c}_{B}\right)$ then $\mathrm{F}$ is closed in $\left(\mathrm{X}, \mathrm{i}_{A}, \mathrm{c}_{A}\right)$ holds, i.e. (1) if for any subset $B$ of $\mathrm{B} \exists$ a subset $A$ of $\mathrm{A}$ such that if any element of $\mathrm{X}$ has one or more attributes form $\dot{B}$ surely in final stage $\Leftrightarrow$ it must had one or more attributes from $A$ surely at initial stage and (2) for any subset $\grave{B}$ of $\mathrm{B} \exists$ a subset $\grave{A}$ of A such that if any element of $\mathrm{X}$ has the possibility all the attributes from $\dot{B}$ finally $\Leftrightarrow$ it had the possibility of all the attributes from $\grave{A}$ initially.

In this case we will make a decision that the set $\mathrm{A}$ of attributes is changed to the set of attributes B.

\subsubsection{Decision Model}

We will say the set of attributes $A$ and $B$ are mutually dependent if $U \subseteq X$ is open(closed) in $\left(\mathrm{X}, \mathrm{i}_{A}, \mathrm{c}_{A}\right)$ iff $\mathrm{U}$ is open(closed) in $\left(\mathrm{X}, \mathrm{i}_{B}, \mathrm{c}_{B}\right)$.

Acknowledgements. I am thankful to the referees for their suggestions and valuable comments to revise the paper.

\section{References}

1. Cattaneo, G.: The Lattice Topological Approach to Roughness Theory by Approximation Spaces. In: Proceedings-Int. Conf. on Rough Sets, Fuzzy Sets and Soft Computing, November 5-7, 2009, pp. 9-74. Serial Pub., New Delhi (2011)

2. Kryszkiewicz, M.: Rough Set Approach to Incomplete Information Systems. Information Sciences 112, 39-49 (1998)

3. Mashhour, A.S., Allam, A.A., Mahmoud, F.S., Khedr, F.S.: On Supra Topological Spaces. Indian J. Pure and Appl. Math. 4(14), 502-510 (1983)

4. Pagliani, P.: Concrete and Formal Pre-Topological Systems and Their Approximate Operators. In: Proceedings-Int. Conf. on Rough Sets, Fuzzy Sets and Soft Computing, November 5-7, 2009, pp. 119-128. Serial Pub., New Delhi (2011)

5. Pagliani, P., Chakraborty, M.K.: A Geometry of Approximation, Rough Set Theory: Logic, Algebra and Topology of Conceptual Patterns, pp. 406-477. Springer, Heidelberg (2008)

6. Pawlak, Z.: Rough Sets. International Journal of Information and Computer Science 11(5), 341-356 (1982)

7. Shao, M.W.: A complete Method to Incomplete Information Systems. In: Yao, J., Lingras, P., Wu, W.-Z., Szczuka, M.S., Cercone, N.J., Ślęzak, D. (eds.) RSKT 2007. LNCS (LNAI), vol. 4481, pp. 50-59. Springer, Heidelberg (2007)

8. Willard, S.: General Topology. Addison Wesley Publishing Company, Reading (1970)

9. Yao, Y.: Constructive and Algebraic Method of the theory of Rough Sets. Information Sciences 109, 21-47 (1998)

10. Zhu, W.: Topological Approaches to Covering Rough Sets. Information Science 177, 1499-1508 (2007) 